\title{
A tipologia ocupacional Erikson-Goldthorpe-Portocarero (EGP): uma avaliação analítica e empírica*
}

Flavio Alex de Oliveira Carvalhaes**

Resumo: As classes sociais são consideradas um conceito sociológico por excelência. Neste artigo, propomos uma avaliação empírica do conceito, motivada por questionamentos contemporâneos que têm sido críticos a análises que recorrem ao conceito de classe como dimensão heuristicamente interessante. Nosso esforço se concentra em uma validação da proposta popularmente conhecida como a tipologia EGP (Erikson-Goldthorpe-Portocarero). Através da utilização de uma técnica estatística, sensível ao padrão dos dados - a análise de classes latentes -, verificamos o padrão de associação da tipologia com aspectos relevantes do mercado de trabalho brasileiro. Como principal resultado que emerge a partir das análises empreendidas, apontamos uma série de restrições à proposta avaliada. Isso indica para a necessidade dos sociólogos e de outros pesquisadores interessados no trabalho com o conceito estarem sensíveis para as particularidades impostas pelo contexto brasileiro que impõe limites não triviais à sua validade empírica.

Palavras chave: mercado de trabalho, análise de classe, tipologias ocupacionais, classe social, EGP.

\section{Introdução}

$\mathrm{N}$ a literatura contemporânea da área temática da sociologia da estratificação social há um questionamento sobre a relevância do conceito de classe para a compreensão de como se estruturam as desigualdades sociais (Pakulski \& Waters, 1996). De forma mais amena, mas igualmente crítica, esse desconforto se manifesta também em propostas que vocalizam fortes críticas a respeito das operacionalizações convencionais do conceito de classe (Grusky \& Weeden, 2008). Neste trabalho, desejamos contribuir para o debate a partir do ponto de vista de como o contexto brasileiro fornece insights sobre as potencialidades e limites da discussão.

Nossa estratégia argumentativa se apoia na apresentação do que pesquisadores estrangeiros e brasileiros entendem como análise de classe, ou seja, os pontos analíticos em comum que definem o objetivo daqueles que defendem que as classes sociais são uma dimensão fundamental para o entendimento de diversos tipos de desigualdade. Ao delinear os pontos mais salientes dessas abordagens, nos preocuparemos em apontar os principais questionamentos e críticas para, em seguida, apresentar as propostas de operacionalização do conceito para pesquisas empiricamente orientadas. Após uma revisão sistemática dos princípios e críticas levantadas
Recebido: 19.09.13

Aprovado: 22.04 .14

\author{
* Agradeço a \\ Adalberto Cardoso, \\ Nelson do Valle Silva, \\ Carlos Antônio Costa \\ Ribeiro e José Alcides \\ Figueiredo Santos \\ pelos comentários \\ feitos ao artigo \\ em suas versões \\ preliminares. Esse \\ trabalho foi escrito \\ durante um estágio \\ de pós-doutorado \\ no Centro Brasileiro \\ de Análise e \\ Planejamento. \\ Agradeço a todos \\ membros da \\ instituição pelo \\ apoio e à professora \\ Nadya Guimarães, \\ pela supervisão, \\ rigor e modelo \\ acadêmico, pessoal e \\ profissional. Também \\ sou grato à Fapesp, \\ que sob o contrato \\ 2013/01764-4, \\ financiou meses de \\ grande aprendizado \\ nas excelentes \\ instituições \\ universitárias do \\ estado de São Paulo. \\ ** Doutor em \\ sociologia (lesp- \\ Uerj), pesquisador \\ do Núcleo \\ Interdisciplinar \\ de Estudos da \\ Desigualdade (Nied) \\ e professor adjunto \\ do Departamento de \\ Sociologia da UFRJ.
}


na literatura, fazemos um exercício para conectar os debates e os dados que temos disponíveis em uma extensa avaliação de como a tipologia analisada se relaciona com outras características ocupacionais do mercado de trabalho brasileiro.

Procedemos de forma diferente em relação a outros pesquisadores do país interessados no assunto. A prática mais comum é tomar as classes sociais como variável explicativa central para o estudo da estruturação de vários tipos de desigualdades: de oportunidades de mobilidade social (Scalon, 1997; Ribeiro, 2007) ou desigualdade de renda (Santos, 2002), por exemplo. Esses e outros trabalhos, apesar de terem a preocupação em delinear quais são os princípios que guiam a operacionalização dos agrupamentos ocupacionais (ou classes) utilizadas (Silva, 2003a; Santos, 2005; Ribeiro, 2007) não se preocuparam em analisar mais detidamente se os princípios analíticos elencados a priori para construir a variável de classe tinham alguma ressonância empiricamente válida. Procedemos de forma oposta. Optamos por fazer uma análise "interna" da validade empírica do conceito, através da operacionalização de dimensões correlatas à classe que nos permitem realizar metodologicamente uma avaliação da validade do conceito. Dados inéditos da caracterização ocupacional no Brasil e uma técnica estatística apropriada para o tratamento do problema que motiva nossa reflexão colocam-nos em uma posição privilegiada para avaliar uma das tipologias ocupacionais mais relevantes na pesquisa sobre desigualdades sociais, o esquema Erikson-Goldthorpe-Portocarero (Erikson, Goldthorpe \& Portocarero, 1979; Erikson \& Goldthorpe, 1992). Esperamos que, com essa avaliação, possamos esclarecer se os questionamentos contemporaneamente levantados pela literatura são válidos ao tentarmos interpretar o mercado de trabalho brasileiro a partir desta tipologia.

\section{Análise de classe: \\ proposta e operacionalização}

Perspectivas inseridas no projeto da análise de classes procuram interpretar como se estrutura a distribuição de um determinado bem ou recurso na sociedade, a partir da compreensão de que o processo de estratificação social é relacional, ou seja, é possível distinguir um conjunto de posições na estrutura produtiva da sociedade suficientemente comuns entre si, que contrastam com outras e que, compartilhadas, indicam o grau de poder social dos indivíduos que nela se inserem (Breen \& Rottman, 1995). Apesar de haver um relativo desacordo sobre quais seriam os critérios teoricamente e empiricamente mais relevantes na operacionalização da variável de classe na sociedade contemporânea, existem algumas interseções entre as diferentes propostas. Todas operam através do estabelecimento de critérios conceituais claros na definição da variável de classe, assim em como ela se liga com o objeto empírico em cada tipo de estudo (Manza \& Brooks, 1996; Grusky \& Sorensen, 1998; Breen, 2005; Wright, 2005b). 
Segundo um dos principais autores a avançar a perspectiva, John Goldthorpe (2002), três considerações devem ser preenchidas para que um trabalho possa ser considerado uma análise de classe:

a. a classe não pode ser construída como uma mera agregação arbitrária de títulos ocupacionais, mas deve conter um fundo conceitual claro, implementado a partir de critérios válidos;

b. análises de resultados específicos (ex: desigualdade de renda) que têm a classe como variável explicativa devem ser capazes de demonstrar regularidades empíricas como forma de apontar a validade do constructo;

c. a própria forma através das quais as classes são conceituadas fornece um ponto de partida para o desenvolvimento de explicações em termos de ação social para as regularidades demonstradas (Goldthorpe, 2002: 214).

Essa seria a contribuição genuinamente sociológica para o estudo da estratificação social das sociedades: o entendimento de que há algum tipo de estruturação subjacente às desigualdades sociais ligadas à divisão social do trabalho. Nessa perspectiva, independente de como abordada ou operacionalizada, a classe ou, em termos mais fracos, a dimensão ocupacional seria uma forma privilegiada de entender aspectos estruturais da distribuição da desigualdade (Sorensen, 1996).

Apesar da existência de divergências sobre como operacionalizar o conceito de classe, há um consenso sobre a importância que a inserção ocupacional dos indivíduos tem para a compreensão da estruturação da desigualdade, ponto de partida para estratégias que pretendem fazer uma utilização empírica do conceito (Erikson \& Goldthorpe, 1992; Wright, 2005a; Weeden \& Grusky, 2012). Diferentes posições no mercado de trabalho dariam acesso a um fluxo distinto de recursos e recompensas desigualmente distribuídos na sociedade (Goldthorpe, 2000; 2007a). A forma de sistematizar a relação entre a estrutura ocupacional e outras características da inserção dos indivíduos no mercado de trabalho que produz distinções entre as diferentes formas de operacionalização do conceito disponíveis na literatura sociológica internacional e nacional. Existe algum desacordo sobre quais seriam os critérios teoricamente mais relevantes na estruturação das classes, se deveríamos nos focar nas relações de exploração inseridas na organização do trabalho (Wright, 1997; 2005b) ou estudar o tipo de contrato que regula as relações laborais (Goldthorpe, 2000; Breen, 2005; Goldthorpe, 2007a).

Neste artigo, estaremos dedicados à avaliação analítica e empírica de uma tipologia ocupacional específica, o esquema Erikson-Goldthorpe-Portocarero (1979), 
1. Aqui seguimos a formulação weberiana clássica, que entende as oportunidades de vida como experiências de afluência ou dificuldade, segurança ou insegurança econômica, oportunidades de prosperar no avanço material ou então de fracassar nesse âmbito segundo o linguajar weberiano (Breen, 2005) popularmente conhecido como EGP. O principal objetivo da proposta é dar conta da relação entre diferentes posições existentes no mercado de trabalho e as oportunidades de vida ${ }^{1}$. Uma das formas de se entender analiticamente as classes seria a consideração da posição que as pessoas ocupam em mercados de trabalho, através do entendimento das relações de emprego. O objetivo de um esquema de classes que se insere dentro dessa perspectiva é diferenciar posições dentro de mercados de trabalho e unidades de produção, em outras palavras, diferenciar as posições em termos das relações de emprego que elas envolvem (Erikson \& Goldthorpe, 1992: 37). Classes, segundo essa abordagem, são constructos relacionados a posições no mercado de trabalho e na divisão social do trabalho, mecanismos centrais de alocação de retornos socialmente desejáveis (Breen \& Rottman, 1995; Breen, 2005).

Essa proposta baseia-se em uma forma de entender algo que é definido como conflito intrínseco às relações de trabalho. Uma distinção essencial na elaboração do esquema é aquela relativa ao estabelecimento da natureza das relações de emprego, que diz respeito ao tipo de regulação que adotam, ou seja, se elas são regidas por relações de serviço (service) ou trabalho (wage-labour). Um dos princípios para distinguir os dois tipos de contrato seria a assimetria informacional envolvida nos fluxos do cotidiano de trabalho, ou seja, as possibilidades de supervisão direta do trabalho envolvida em uma ocupação específica (Goldthorpe, 2007b). Contratos de trabalho seriam caracterizados por envolver poucos problemas de supervisão, estariam relacionados com tarefas bem determinadas e teriam poucos problemas de monitoramento, porque a tarefa do empregado pode ser, a princípio, inspecionada. Outras características marcantes seriam a menor estabilidade do emprego e as menores possibilidades de mobilidade econômica. O contrato de serviço, por sua vez, envolve uma assimetria informacional relativamente grande, sua inserção se dá em um contexto burocrático que envolve uma troca de mais longo prazo e que se realiza de forma mais difusa. Os retornos não são ligados diretamente à produtividade, mas também a elementos prospectivos, como promoções, segurança, estabilidade. Usualmente, as tarefas estão ligadas ao exercício de autoridade delegada, onde é necessário deter algum tipo de conhecimento específico e expertise para atuar (Breen, Halpin \& Economic and Social Research Institute., 1989; Erikson \& Goldthorpe, 1992; Breen, 2005; Goldthorpe, 2007b).

Fora esses tipos de inserção, via mercado, os autores da proposta também se esforçam para entender o vínculo que não passa necessariamente pelo emprego. Um primeiro tipo de inserção relacionado a essa questão é o trabalhador "conta própria", que tem em seu trabalho uma relativa autonomia e o controle dos meios de produção e das condições de trabalho. A tipologia ocupacional EGP preocupa-se em compreender essa dimensão de forma explícita, apesar do principal foco analítico estruturante da tipologia ser a venda de trabalho no mercado. As outras categorias 
presentes na tipologia têm a marca da tentativa de entendimento do impacto da divisão dos setores econômicos na divisão do trabalho, com o foco em trabalhadores ou proprietários do meio rural, algo relativamente residual nas economias mais desenvolvidas, mas ainda presente, em termos tanto de mão de obra ocupada como de geração de riqueza, em contextos como o brasileiro (Santos, 2002).

Podemos contrastar a proposta do EGP com as outras tipologias ocupacionais disponíveis na literatura sociológica brasileira sobre o tema. Tínhamos, a princípio, no mínimo três opções à disposição, duas das quais mais próximas de princípios de operacionalizações neoweberianas (Silva, 2003a; Santos, 2005; Ribeiro, 2007) e uma neomarxista (Santos, 2005). As três realizam um esforço para incorporar aspectos dos setores econômicos brasileiros através da distinção entre "indústrias modernas" e "indústrias tradicionais", feitas por Nelson do Valle Silva (2003a; 2003b), incorporadas também em Carlos Antônio Costa Ribeiro (2007), ou distinções do setor rural, elaboradas por José Alcides Figueiredo Santos (2005). Outra preocupação explícita é a criação de categorias para dar conta do vasto setor informal do mercado de trabalho brasileiro, como a presença de categorias que refletem o serviço doméstico existente nas três tipologias, além da presença de categorias para dar conta do trabalho por conta própria, constante também nessas operacionalizações². Os trabalhos desses autores mostram, de diversas formas, a importância que o conceito de classe tem para a compreensão de diversos tipos de desigualdades. Todos seguem a mesma estratégia: estabelecem certos critérios previamente, operacionalizam as tipologias a partir do agrupamento combinado de ocupações com outras dimensões, geralmente posição na ocupação e setor de atividade econômica da ocupação. Analiticamente, não discordamos dessas diferentes propostas, as três parecem satisfatórias, a julgar pelos próprios resultados mobilizados por seus autores para compreender os problemas que os ocupavam, a desigualdade de oportunidades e transmissão intergeracional da desigualdade (Ribeiro, 2007) e a desigualdade de rendimentos (Santos, 2002; Silva, 2003b), por exemplo.

Infelizmente, duas limitações se impõem para seguirmos as propostas brasileiras que tentam adaptar para nosso contexto as propostas sobre classes. A primeira é de natureza técnica. Essas tipologias são desenvolvidas tendo como foco explícito os dados da Pesquisa Nacional de Amostragem Domiciliar (Pnad) feita pelo Instituto Brasileiro de Geografia e Estatística (IBGE). Essa pesquisa tem um tamanho amostral atípico em relação a outros inquéritos populacionais. Como ela tem interesses tanto acadêmicos como administrativos (monitorar o desemprego em regiões metropolitanas, por exemplo), seu desenho amostral abarca, em média, 400 mil entrevistas. Isso permite que as tipologias ocupacionais propostas na literatura sejam extremamente refinadas, chegando a propor 19 (Ribeiro, 2007), 18 (Silva, 2003a) ou 13 categorias (Santos, 2005), dado o tamanho das amostras que apoiam os estudos
2. Atenção semelhante é dada por trabalhos que também têm classes como dimensão explicativa central para o entendimento da desigualdade na América Latina, que se concentram no papel da informalida de na estruturação das desigualdades, como mostram análises feitas por Torche (2006), para o Chile, e também reflexões mais marcadas por um esforço comparativo (Portes \& Hoffman, 2003; Portes \& Haller, 2005; Portes, 2010). 
dos autores. Situações menos generosas do ponto de vista do tamanho amostral tornam inviável o trabalho com tamanho detalhamento. Essas tipologias também dependem diretamente de outros tipos de informação contingentes aos dados do IBGE, como setores de atividade ou a posição na ocupação.

Esses limites tornam atrativa a avaliação da tipologia EGP (Erikson, Goldthorpe \& Portocarero, 1979) para a realidade brasileira. Essa oferece vantagens em termos de apresentar menos categorias, portanto é mais flexível para amostras de tamanhos menores. Ela também não depende de nenhuma variável disponível somente em dados como a Pnad, como a de setores de atividade do IBGE. Sua operacionalização se baseia apenas da informação sobre a ocupação e algumas outras poucas variáveis de caracterização dessa inserção.

Associada a essa flexibilidade está uma discussão teoricamente relevante a partir de reflexões sobre as direções do capitalismo contemporâneo. Diretamente relacionados à posição de classe estariam aspectos da vida econômica tais como segurança, estabilidade e prospectos de avanços economicamente relevantes. Não seria exagerado afirmar que indivíduos em classes distintas vivem em "mundos econômicos" bem diferentes, não apenas no que diz respeito a seu bem-estar material, mas ainda no tocante a todo um espectro de riscos e de oportunidades vividos (Goldthorpe \& Marshall, 1997; Goldthorpe \& McKnight, 2006: 129).

Do ponto de vista empírico, essa proposta teórica foi demonstrada em diversos

TABELA 1

DISTRIBUIÇÃO DA TIPOLOGIA OCUPACIONAL. INDIVÍDUOS ENTRE 25 E 65 ANOS (BRASIL, 2008)

\begin{tabular}{|l|r|r|}
\hline \multicolumn{1}{|l|}{} & N & \multicolumn{1}{c|}{$\%$} \\
\hline I: Profissionais, alto nível & 388 & 7,39 \\
\hline II: Profissionais, baixo nível & 559 & 10,65 \\
\hline IIIa: Não manual de rotina & 499 & 9,51 \\
\hline IIIb: Serviços e vendas & 321 & 6,12 \\
\hline IVa: Conta própria com empregados & 388 & 7,41 \\
\hline IVb: Conta própria sem empregados & 865 & 16,49 \\
\hline V: Supervisores do trabalho manual & 93 & 1,78 \\
\hline V: Trabalhador manual qualificado & 323 & 6,15 \\
\hline VIla: Trabalhador manual não qualificado & 1.362 & 25,97 \\
\hline VIIb: Trabalhadores agrários & 80 & 1,53 \\
\hline IVc: Conta própria agrário & 367 & 7,00 \\
\hline Total & 5.244 & 100,00 \\
\hline Fonte: Pesquisa Nacional das Dimensões Sociais da Desigualdade. Elaboração própria.
\end{tabular}
trabalhos, focados em diferentes problemas de pesquisa, como consumo cultural (Chan \& Goldthorpe, 2007; Chan et alii, 2011), mobilidade social (Erikson \& Goldthorpe, 1992), trajetórias ocupacionais (Goldthorpe \& McKnight, 2006), entre outras. Ou seja, a tipologia que usaremos é satisfatória do ponto de vista analítico, flexível do ponto de vista empírico, e teve sua validade testada em uma variedade significativa de contextos e questões de pesquisa. Portanto, nossa escolha justifica-se tanto por critérios pragmáticos como substantivos. Basicamente, a ti- 
pologia ocupacional EGP sugere as classes representadas na Tabela 1, que foi ajustada para os dados que utilizaremos para a nossa avaliação empírica.

\section{Análise de classes: críticas e limites}

Há três categorias distintas de críticas que podemos mobilizar para apontar insuficiências de abordagens que defendem a análise de classes. A primeira, de natureza mais teórica, questiona a própria viabilidade heurística do conceito para interpretação do mundo contemporâneo. O segundo grupo de críticas é "interno" aos trabaIhos na área da estratificação social, e os autores dessas propostas até concordam com a premissa de que classe é uma forma relevante de compreensão do mundo contemporâneo mas tecem severas críticas à forma como tem sido tratada. Por fim, um terceiro bloco de críticas pode ser mobilizado através das próprias especificidades que o contexto brasileiro (e no limite, latino-americano) impõe ao trabalho que dispensa esse tipo de abordagem. Iremos abordar cada um desses blocos, começando pelo primeiro.

Autores destacam o enfraquecimento das classes baseados principalmente em um argumento sobre a falta de relevância do conceito para compreensão da ação coletiva, argumentando em uma direção que distingue o fortalecimento de outros tipos de clivagem que seriam sobrepostos a elas, como laços comunitários de moradia, raça, sexo, dissídios coletivos não relacionados ao trabalho, dentre outras (Pakulski \& Waters, 1996). Há também argumentos mais focados ao tema da classe em si, que destacam que transformações estruturais do capitalismo teriam levado a uma diminuição da importância do trabalho como fonte identitária para os indivíduos, que procurariam outros tipos de vínculos em um mundo pós alguma coisa (moderno, fordista, salarial, a lista é grande) (Manza \& Brooks, 1996). Esse tipo de mobilização teve alguma voga, principalmente no período mais próximo à derrocada do bloco soviético. No entanto, devido ao fato de os trabalhos empíricos que continuaram se baseando no conceito de classe invariavelmente produzirem resultados empiricamente relevantes, o impacto desse tipo de crítica foi pouco sentido, e, portanto não nos aprofundaremos em seus argumentos.

O segundo bloco de críticas levanta questionamentos mais interessantes do nosso ponto de vista. As críticas internas à análise de classes levantam problemas de operacionalização conceitual. Independentemente de indicar o princípio analítico eleito como o mais relevante para a pesquisa empírica, abordagens ligadas à análise de classe destacam ex ante quais seriam os conceitos heuristicamente importantes para o agrupamento de um conjunto de ocupações sobre o mesmo rótulo (Grusky \& Sorensen, 1998; Grusky \& Galescu, 2005; Grusky \& Weeden, 2006). Autores in- 
satisfeitos com os critérios de operacionalização dessas abordagens fazem uma crítica simples, mas certeira: se a preocupação fundamental recai sobre relações contratuais ou de exploração no mercado de trabalho, por que classificar os resultados sob o nome de classe? No limite, outros rótulos poderiam ser criados, talvez mais próximos do que está sendo investigado, e ao invés de classe proprietária falaríamos de classe exploradora, ou então a troca seria entre classe de administradores e profissionais de alto nível para detentores de contratos de prestação de serviço. A perda de elegância seria compensada por uma maior precisão conceitual (Grusky \& Sorensen, 1998). Na proposta avançada pelos autores que defendem essa perspectiva, ao invés de se trabalhar com grandes agregados ocupacionais em algum tipo de tipologia, chamado por eles de macroclasses, deveríamos deslocar nossa atenção para as ocupações em si, ou seja, para as microclasses (Grusky \& Galescu, 2005).

Apesar de acharmos interessantes as desconfianças presentes na autointitulada proposta neodurkheimiana, suas limitações chamam mais atenção do que suas possíveis qualidades. A nosso ver, é um certo exagero advogar por especificidades de cada ocupação do mercado de trabalho ao invés de tentar ver pontos comuns e situações compartilhadas por certas especificidades no mercado de trabalho. Nessa perspectiva, ao invés de tratarmos uma inserção ocupacional de forma genérica, pelo compartilhamento de certas especificidades, deveríamos destacar suas diferenças. Por exemplo, ao invés de falarmos sobre profissionais liberais, deveríamos nos referir especificamente a dentistas, advogados, médicos e similares. Esse aumento de complexidade não parece justificar os ganhos analíticos com a troca de estratégia. Do ponto de vista operacional - e metodológico também - a troca impõe severas limitações. Além de não haver garantias de que esse nível de análise leve a uma maior confiabilidade nas pesquisas (em realidade, o inverso é mais plausível), os modelos multivariados que viraram lugar comum em diversos estudos sobre estruturação da desigualdade, sejam eles sociológicos ou de outras disciplinas, teriam sérias limitações para incorporar uma abordagem tão ineficiente do ponto de vista operacional. Outro limite - do contexto brasileiro - também se impõe: a trajetória da consolidação do mercado de trabalho nacional e suas inflexões não apontam para uma cristalização ou um fortalecimento de nichos ocupacionais, pelo contrário (ponto que iremos expandir abaixo). Com todas essas limitações, parece-nos prudente guardar dessa abordagem apenas sua desconfiança com as abordagens tradicionalmente defendidas. Em nossa opinião, essa foi a maior contribuição dessa perspectiva para os nossos presentes propósitos (para uma revisão mais profunda e testes empíricos, ver Carvalhaes e Souza, 2014).

Por fim, resta-nos a consideração de possíveis limites impostos à abordagem da análise de classes pelo contexto brasileiro. Tentaremos mobilizar tanto caracterís- 
ticas relevantes apontadas na literatura sobre a estruturação de nosso mercado de trabalho, quanto a maneira como outros pesquisadores incorporaram essas características em suas propostas de operacionalização dessa dimensão de classe para o Brasil e, indiretamente, também para o contexto latino-americano. O principal ponto levantado como estruturador das classes é o mercado de trabalho e como as pessoas nele se inserem. Essa simples afirmação não é trivial para o contexto brasileiro e latino-americano. Incapaz de expandir as relações salariais para um contingente significativo da população, o modelo de desenvolvimento de nosso e de outros países do continente é marcado por significativas clivagens, sendo uma das principais o eixo formalidade $\times$ informalidade (Portes \& Hoffman, 2003; Portes \& Haller, 2005; Cardoso, 2008). Sobreposta a essa situação, ainda há um intenso processo de desemprego recorrente para significativas parcelas da população, apresentando características específicas que são capazes de se posicionar no mercado de trabalho apenas de forma intermitente e provisória (Guimarães, 2002) ou então recorrendo a processos de intermediação do trabalho que impõem sérios limites à interpretação clássica do estabelecimento dos vínculos no mercado de trabalho (Guimarães, 2008).

Uma vez realizada a exposição sobre as possibilidades e os limites da análise de classes e do trabalho com uma de suas notórias vertentes, podemos resumir as intenções da avaliação empírica que segue. São conhecidos os paradoxos do nosso mercado de trabalho, que encontra grande parte de seu contingente ocupando posições precárias, informais e desprotegidas. Nesse contexto, não é trivial nos questionarmos sobre a plausibilidade de propostas que pretendem interpretar essa situação como "estruturada", passível de ser compreendida e agrupada sob grandes rótulos. As características próprias ao nosso contexto reforçam a inquietação surgida na literatura sociológica e impõe uma desconfiança sobre a relevância do conceito de classe. O principal eixo analítico que guia a construção da tipologia que iremos avaliar refere-se ao mercado de trabalho e aos tipos de vínculos nele estabelecidos. A tipologia também se esforça para sistematizar aquelas situações que oferecem outros tipos de vínculo igualmente fortes, ou setoriais (no caso da agricultura), ou vinculada ao mercado de forma híbrida (como os trabalhadores por conta própria). Como a tipologia ocupacional que iremos avaliar - o esquema de classes Erikson-Goldthorpe-Portocarero (Erikson, Goldthorpe \& Portocarero, 1979) - foi criada para um contexto socioeconômico e produtivo muito distinto do brasileiro, podemos questionar se as características do mercado de trabalho no Brasil impõem desafios empíricos a essa proposta ou não. Portanto, a pergunta que guia o exercício empírico a seguir é: qual é a ressonância empírica dos princípios analíticos elencados como relevantes para a operacionalização do esquema classes EGP para o caso brasileiro? 
De forma mais direta, podemos perguntar: os agrupamentos ocupacionais tradicionalmente feitos pelos sociólogos dedicados ao estudo da desigualdade "medem" o que eles mesmos argumentam medir? Podemos ser mais precisos: os princípios analíticos elencados pela literatura internacional, especialmente aquelas propostas na tipologia ocupacional adotada pelo esquema EGP (Erikson, Goldthorpe \& Portocarero, 1979) são suficientes na operacionalização do conceito de classe para a realidade brasileira? Quais são, empiricamente, as associações entre as categorias ocupacionais mobilizadas na tipologia EGP e as características do mercado de trabalho brasileiro? Nossa principal desconfiança recai sobre a relevância analítica colocada sobre a estruturação do mercado de trabalho e os diferentes tipos de contrato que regem os vínculos presentes nele. Ao invés de tentar preestabelecer quais são os critérios que deveriam ser elencados para a construção de uma tipologia - o que já foi feito -, tentaremos empreender um exercício empírico que mobilize resultados que podem informar nosso julgamento para responder a essas inquietações.

\section{Dados e estratégia analítica}

Os exercícios de validação empírica de constructo são práticas comuns em áreas relacionadas às ciências sociais, como a epidemiologia social ou psicologia social, mas são práticas menos comum na sociologia empiricamente orientada. Isso pode levar a, no mínimo, duas consequências pouco desejadas: ambiguidade conceitual e falta de clareza. Quando um conceito é operacionalizado ex ante e utilizado diretamente em análises como variável explicativa, as evidências de sua validade são tratadas a partir de sua significância estatística em um determinado modelo multivariado. Entretanto, não há nenhuma garantia sobre o que se assegura medir ser o que se está realmente medindo na situação avaliada (Evans \& Mills, 1998). Recentemente, esse espaço de contribuição foi ocupado por alguns sociólogos europeus e norte-americanos, que passaram a se dedicar à avaliação dos conceitos caros à área, como classe social, de especial interesse para o presente projeto (Evans \& Mills, 2000). Exercícios semelhantes são raros no Brasil, na operacionalização de conceitos sociológicos em geral, e também naqueles caros à pesquisa sobre desigualdades. Sendo assim, é oportuno que uma contribuição seja feita para explorar empiricamente alguns princípios analiticamente levantados.

Felizmente há dados disponíveis para o exercício de validação que propomos com o acesso aos microdados do survey realizado no âmbito do Instituto do Milênio - Pesquisa das Dimensões Sociais das Desigualdades (PDSD). Esse survey, empreendido em 2008, tem amostra probabilística representativa para todo Brasil, quando foram realizadas entrevistas em 8.048 domicílios. Foram levantados dados sobre emprego, saúde, justiça distributiva, experiência discriminatória, comportamento político, 
entre outros. Um dos módulos continha um conjunto de questões que caracteriza a inserção ocupacional dos indivíduos, de onde extraímos as variáveis necessárias para a realização de nosso exercício empírico. Para a construção da variável de classe, temos a informação da ocupação e das demais variáveis necessárias à sua operacionalização de acordo com critérios internacionais. O acesso a essa base de dados coloca-nos em posição privilegiada. Por um lado, podemos operacionalizar a variável EGP da forma mais rigorosa possível, seguindo as orientações internacionais disponíveis. Isso se deve ao fato de termos na mesma base de dados informações sobre a ocupação da pessoa e outras características não levantadas nas pesquisas do IBGE. Particularmente importante na construção dessa tipologia é a dimensão da autoridade, operacionalizada através da pergunta se o indivíduo exerce tarefas de supervisão e quantas pessoas supervisiona. Essa variável, aliada à informação da ocupação e de posição na ocupação, permite operacionalizar a variável EGP seguindo rigorosamente todos os passos da literatura internacional (Ganzeboom \& Treiman, 1996) ${ }^{3}$.

No entanto, a rigor, não temos variáveis que avaliam o constructo de classe diretamente. Para reproduzir os estudos mencionados anteriormente, deveríamos ter acesso a variáveis que refletissem as condições de promoção no emprego, sua estabilidade e, principalmente, questões que tratassem mais diretamente a assimetria informacional intrínseca às ocupações, de forma que pudéssemos avaliar mais diretamente indicadores do tipo de contrato que rege o vínculo dos indivíduos com o mercado de trabalho, se de serviço (service) ou trabalho (labour). Acreditamos ter disponível em nossa base de dados outros critérios relevantes de caracterização ocupacional, apresentados abaixo. A indisponibilidade de variáveis que teriam o propósito de avaliar diretamente os princípios analíticos levantados na literatura é amenizada pela presença das variáveis de caracterização ocupacional, extremamente relevantes no contexto do mercado de trabalho brasileiro, como mostraremos adiante. Além disso, a técnica estatística por nós utilizada, detalhada na seção seguinte, é centrada em pessoas e não em variáveis, o que nos permite contornar os limites das variáveis disponíveis. Em análises centradas em variáveis (variable oriented approaches), a ênfase está na identificação das relações entre variáveis, e se assume que essas relações se mantêm entre todas as pessoas da amostra avaliada e, no limite, para a população, já que as técnicas têm componentes inferenciais. Análises fatoriais exploratórias são um exemplo de técnica centrada em variáveis. Em uma análise centrada em pessoas (person oriented approaches), a ênfase está nos indivíduos, ou seja, de um ponto de vista operacional, isso quer dizer estudar os padrões de respostas dos indivíduos e sua relevância para o problema sob consideração. A técnica por nós utilizada insere-se nesse quadro, com a intenção de procurar grupos de indivíduos que exibam padrões similares de características e que possam ser agrupados em algum perfil latente de características (Collins \& Lanza, 2010: 8).
3. Seguimos as syntaxes feitas por Harry Ganzeboom e disponíveis na página <http:// home.fsw.vu.nl/hbg. ganzeboom/ismf/..\%5 Cisco08\%5Cindex. htm>. 
TABELA 2

VARIÁVEIS UTILIZADAS NA ANÁLISE DE CLASSES LATENTES

\begin{tabular}{|c|c|c|}
\hline & \\
\hline & $\mathrm{N}$ & $\%$ \\
\hline \multicolumn{3}{|c|}{ Número de horas trabalhadas } \\
\hline Menos de 8 horas & 1.173 & 22,37 \\
\hline 8 horas & 2.503 & 47,73 \\
\hline Mais de 8 horas & 1.568 & 29,90 \\
\hline \multicolumn{3}{|c|}{ Posição na ocupação } \\
\hline Empregado setor público & 647 & 12,34 \\
\hline Empregado setor privado com carteira & 1.881 & 35,86 \\
\hline Empregado setor privado sem carteira & 613 & 11,70 \\
\hline Conta própria & 1.988 & 37,90 \\
\hline Empregador & 116 & 2,20 \\
\hline \multicolumn{3}{|c|}{ Contribuição para previdência } \\
\hline Não contribui & 4.458 & 85,02 \\
\hline Contribui & 786 & 14,98 \\
\hline \multicolumn{3}{|c|}{ Filiação sindical } \\
\hline Não é filiado & 3.911 & 74,59 \\
\hline É filiado & 1.333 & 25,41 \\
\hline \multicolumn{3}{|l|}{ Licença médica e férias } \\
\hline Sem nenhum dos direitos & 2.562 & 48,86 \\
\hline Com direito a férias, licença ou ambas & 2.682 & 51,14 \\
\hline \multicolumn{3}{|c|}{ Forma de pagamento } \\
\hline Outras formas de pagamento & 2.098 & 40,02 \\
\hline Pagamento mensal & 3.146 & 59,98 \\
\hline \multicolumn{3}{|c|}{ Salário bruto em número de salários mínimos (valores de 2008) } \\
\hline 0 a 3 Salários Mínimos & 4.154 & 79,22 \\
\hline Mais de 3 Salários Mínimos & 1.090 & 20,78 \\
\hline \multicolumn{3}{|c|}{ Setor de atividade da ocupação (usada como dummies na LCA) } \\
\hline Atividades agrárias e agropecuárias & 424 & 8,08 \\
\hline Indústria (transformação, construção, moderna) & 917 & 17,48 \\
\hline Comércio & 827 & 15,77 \\
\hline Outras atividades & 309 & 5,89 \\
\hline Serviços & 664 & 12,67 \\
\hline Administração pública & 2.104 & 40,12 \\
\hline
\end{tabular}

Fonte: Pesquisa Nacional das Dimensões Sociais da Desigualdade. Elaboração própria.

Assim, tiramos proveito desse recurso metodológico para fazer uma avaliação substantiva da ressonância empírica dos princípios analíticos elencados mobilizando as outras variáveis de caracterização ocupacional presentes na base, como "número de horas trabalhadas", "posição na ocupação" e as demais variáveis elencadas na Tabela 2. Por meio de uma modelagem em dois passos, podemos avaliar se indivíduos que compartilham certas características pertencem a uma mesma classe 
latente. Em seguida, podemos avaliar como essas classes latentes se relacionam com a variável de classe que temos disponível. Dessa forma, podemos analisar o problema a partir de como ele emerge dos dados e do perfil de distribuição da amostra que temos disponível, em um exercício semelhante ao que outros pesquisadores fizeram no contexto internacional (Birkelund, Goodman \& Rose, 1996; Evans \& Mills, 1998; 1999; 2000).

Nosso principal método de análise é a estimação de um modelo de classes latentes (latent class analysis) ${ }^{4}$. A ideia básica dessa técnica é que há uma distribuição latente (não observada) de alguma dimensão que pode ser representada através da associação de uma série de variáveis categóricas, tomadas como indicadoras de uma tipologia não diretamente mensurada. Dado o pertencimento a uma categoria latente, as variáveis observadas são independentes entre si. O objetivo é explicar a associação entre um conjunto de variáveis categóricas observadas em termos de estrutura latente hipotética (no nosso caso, as dimensões relevantes do mercado de trabalho brasileiro e a capacidade da tipologia EGP em captá-la). A intenção implícita no modelo é conseguir uma representação de um conjunto $\mathcal{X}$ de variáveis (no nosso caso 15) através de um número de dimensões menor, logo, mais simples (McCutcheon, 1987; Hagenaars \& McCutcheon, 2002; Collins \& Lanza, 2010).

O termo latente significa que uma variável, não medida diretamente, é proposta. Ela é medida indiretamente por duas ou mais variáveis observadas, logo, sujeitas a mensuração. A análise prossegue da seguinte forma. Modelos são especificados assumindo que um número mínimo de classes latentes permeia as variáveis observadas. Em cada passo, o modelo adiciona um parâmetro até chegar ao número máximo de classes latentes possíveis, que se igualaria ao número de variáveis possivelmente incluídas no modelo.

sucesso dos ajustes pode ser avaliado de duas formas. Uma, são os ajustes da modelagem, ou seja, critérios de escolha do modelo final que são um balanço entre indicadores estatísticos (Chi Quadrado, Likelihood Ratio e as estatísticas bayesianas BIC e AIC), mas também um balanço analítico entre parcimônia e relevância substantiva daquele resultado. Ao contrário de outros métodos multivariados, que recaem sobre testes de hipóteses convencionais, essa é uma técnica exploratória, que permite certo grau de
FIGURA 1.

Modelo de ANÁlise de Classes Latente (LATENT CLASS ANALYSIS)

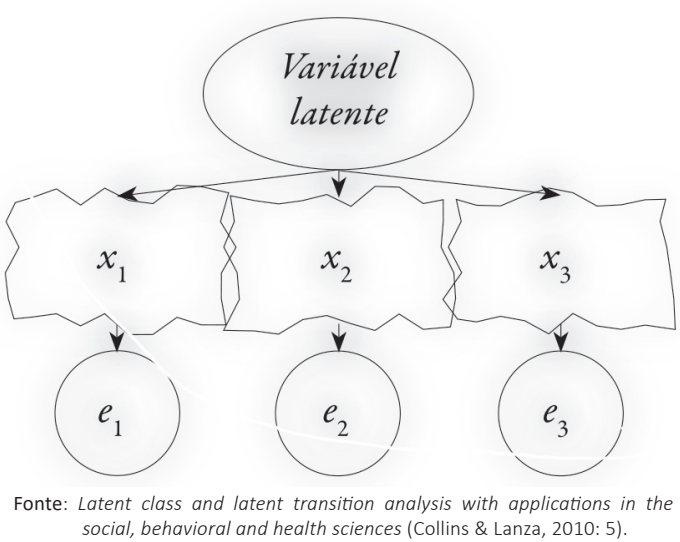

4. É apenas uma coincidência estarmos discutindo uma teoria nomeada análise de classes e avaliar um conceito diretamente vinculado dessa perspectiva com uma técnica chamada análise de classe latente. Como esperamos deixar claro, essa é uma técnica para entender padrões de variação entre qualquer conjunto de indicadores categóricos. 
subjetividade do pesquisador em sua tomada de decisão pelo modelo final. Outro critério de avaliação são os resultados da associação dos indicadores observados com as classes latentes observadas (McCutcheon, 1987; Hagenaars \& McCutcheon, 2002; Collins \& Lanza, 2010). A Figura 1, acima, ilustra a intuição da técnica.

Esses modelos são adequados para os nossos propósitos, pois não fazem suposições sobre a distribuição das variáveis e são desenvolvidos especialmente para a análise de variáveis categóricas. Essa estratégia permite identificar princípios organizadores subjacentes a um conjunto complexo de indicadores, de forma que é possível avaliar se há algum princípio organizador que identifica grupos homogêneos entre si. Os resultados do modelo permitem, sinteticamente, a análise de um conjunto extenso de dados e suas associações, que não seriam passíveis de serem analisadas separadamente através de tabelas bivariadas, por exemplo. Em nosso caso, teremos a oportunidade de identificar se há algum tipo de característica ocupacional que emerge entre indivíduos que compartilham inserções semelhantes no mercado de trabalho. Poderemos saber, por exemplo, se a fronteira entre formalidade e informalidade é captada pelos indicadores que utilizamos ou não. Além disso, saberemos com qual setor de atividade econômica esta fronteira é mais relevante, ou qual perfil pode existir como marcador dessas fronteiras.

O que desejamos saber é se há um padrão de respostas que emerge como mais frequente do que outros. Como trabalhamos com indicadores categóricos, teríamos de realizar uma tabulação de todas variáveis de nosso interesse em uma tabela de contingência (Collins \& Lanza, 2010: 27). Formalmente, em uma situação com $j=1, \ldots, J$ variáveis observadas, e que a variável $j$ tenha $r j=1, \ldots, R J$ categorias de resposta, é feita uma tabela de contingência que é uma tabulação entre as $J$ variáveis presentes que tem $W=\prod_{j=1}^{J} R_{j}$ células. Com nossos dados, podemos relembrar o número de células $W$ com que trabalharemos. Temos $J=14$ variáveis. Assim, podemos pegar a primeira variável da especificação, número de horas trabalhadas e posição na ocupação a título de exemplo. Ela tem três alternativas de resposta, portanto $R_{1}=3$, para a segunda variável, posição na ocupação, o número de opções é cinco, logo $R_{2}=5$, e assim por diante. Dessa forma $W_{1}=3 * 5 * 211 * 11$, o que totaliza 675.840 células. Para cada célula dessa tabela $W$, existe correspondente um padrão de resposta completo, que é um vetor das respostas as $J$ variáveis, representadas por $y=\left(r_{1}, \ldots, r_{\mathrm{j}}\right)$. Se $Y$ se refere a um conjunto de padrões de resposta, $Y$ tem $W$ linhas e $J$ colunas. Cada padrão de resposta $y$, portanto, é associado com uma probabilidade $P(Y=y)$, e $\sum P(Y=y)=1$.

O modelo é representado nas equações abaixo. A ideia básica da técnica é captar associações entre um conjunto de variáveis, consideradas indicadores de uma tipologia não observada, que podem ser resumidas por um número menor de categorias 
latentes obtidas através de um procedimento estatístico. Dado o pertencimento em uma categoria latente, supõe-se que as variáveis usadas na avaliação são independentes entre si.

$$
P(Y=y)=\sum_{c=1}^{c} \gamma c \prod_{j-1}^{J} \prod_{r j=1}^{R j} p_{j, r_{j} j e}^{I\left(y_{j}=r_{j}\right)} \text { (Equação 1) }
$$

Onde $y_{j}$ representa o elemento $j$ de um padrão de resposta $y$. A função indicadora $I\left(y_{j}=r_{j}\right)$ é igual 1 quando a resposta a variável $j=r_{j}$ e 0 em caso contrário (essa função é uma estratégia para retornar o parâmetro de interesse $p$ para ser multiplicado e retornar seu valor). Sendo assim, a Equação 1 expressa a probabilidade de observar um vetor particular de resposta como função das probabilidades de pertencimento em cada classe latente (os parâmetros gamma) e as probabilidades de observar cada resposta, dado o pertencimento condicional a cada classe latente (os parâmetros rhos). Os modelos foram especificados no software SAS 9.0, com os pacotes Proc LCA \& Proc LTA (através do pacote Proc LCA \& Proc LTA - NVersion 1.2.7 [Software], 2011; Lanza et alii, 2011).

\section{Resultados}

Para ajustar nossos modelos, procedemos da seguinte forma: especificamos vários modelos com todas as variáveis apresentadas acima, acrescentando um parâmetro de variável latente por vez. A lógica subjacente à nossa estratégia é tirar proveito do padrão de variação presente a cada passo, cada etapa do ajuste servindo de base comparativa para o passo seguinte. Ao proceder dessa maneira, podemos compreender o que acontece quando ajustamos um parâmetro adicional aos dados, e, dessa forma, podemos ter uma ideia se o padrão de associação que emerge se sustenta à medida do prosseguimento da análise.

Os critérios selecionados para avaliação dos modelos e apresentados nas tabelas abaixo são as estatísticas típicas de análises de modelos deste tipo, como a likeli-hood-ratio statistic $\mathrm{G}^{2}$, e as estatísticas BIC e AIC. Esse tipo de estatística é preferível na análise do ajuste dos modelos, que é muito afetado por um problema de células vazias (sparseness). Com o uso do número de variáveis descritos acima, vários dos perfis possíveis de serem identificados na amostra não o são, e estatísticas que dependem da distribuição das células na tabela, como a estatística $\mathrm{G}^{2}$ devem, preferencialmente, ser evitadas (Collins e Lanza, 2010: 85). Na escolha final do ajuste dos modelos, os critérios estatísticos são contrabalançados por critérios substantivos. O padrão de associação identificado também está sujeito às reflexões teóricas que orientam a construção do modelo e dos dados que o alimentam. A junção de ambas as considerações, adicionada da procura de um resultado parcimonioso, guiaram a seleção dos resultados escolhidos apresentados a seguir. 
TABELA 3

AJUSTE DOS MODELOS DE ANÁLISE DE CLASSES LATENTES, COM EGP

\begin{tabular}{|c|c|c|c|c|c|c|c|c|c|}
\hline $\begin{array}{l}\text { Número } \\
\text { de LCAs }\end{array}$ & $\begin{array}{l}\text { Log Like- } \\
\text { lihood }\end{array}$ & $\begin{array}{l}\text { Graus de } \\
\text { Liberdade }\end{array}$ & $\mathrm{G}^{2}$ & $\mathrm{AIC}$ & $\mathrm{BIC}$ & CAIC & $A B I C$ & Entropia & $\begin{array}{c}\text { Efeito de } \\
\text { design }\end{array}$ \\
\hline 2 & -55.198 & 337.864 & 27.921 & 28.031 & 28.403 & 28.458 & 28.228 & 0,93 & 1,46 \\
\hline 3 & -53.443 & 337.836 & 24.412 & 24.578 & 25.138 & 25.221 & 24.875 & 0,96 & 1,13 \\
\hline 4 & -51.980 & 337.808 & 21.485 & 21.707 & 22.456 & 22.567 & 22.104 & 0,95 & 1,16 \\
\hline 5 & -50.783 & 337.780 & 19.091 & 19.369 & 20.308 & 20.447 & 19.866 & 0,97 & 1,15 \\
\hline 6 & -49.685 & 337.752 & 16.895 & 17.229 & 18.357 & 18.524 & 17.826 & 0,97 & 1,12 \\
\hline
\end{tabular}

Fonte: Pesquisa das Dimensões Sociais da Desigualdade, elaboração própria.

Ao analisar os resultados dos ajustes do modelo, ficamos entre uma solução com 4 ou 5 classes latentes. Como previamente apontado, a escolha não se baseia somente pelas estatísticas de ajuste dos modelos porque estamos igualmente interessados em ver como os resultados emergem à medida que adicionamos parâmetros (cada classe latente). Assim, os critérios fundamentais para análise dos resultados foram um balanço entre sua parcimônia, seu significado substantivo e critérios estatísticos. Não faria sentido tentar reproduzir uma solução que superasse cinco classes latentes, porque estaríamos nos aproximando de um número próximo ao número máximo de categorias da variável que motiva esse estudo, ou seja, as 11 classes postuladas pela tipologia EGP.

Embora esse resultado guie o limite de nossa interpretação, o interesse está em outro tipo de resultado fornecido pela modelagem. Nas tabelas, apresentamos probabilidades condicionais para cada item-resposta das variáveis selecionadas para o modelo. A interpretação dessa probabilidade é similar à realizada com a utilização de loadings de uma análise fatorial, ou seja, ela guia o "significado" do agrupamento sugerido em cada especificação do modelo. No entanto, ao contrário da análise fatorial, devemos estar atentos ao padrão de variabilidade dessas probabilidades em diversas especificações do modelo (com 2, 3, 4, ... N classes latentes), uma vez que os padrões refletem probabilidades condicionais e são especificados de acordo com o número de classes latentes ajustado em cada passo da modelagem (Collins \& Lanza, 2010: 50). As tabelas apresentam os principais parâmetros gerados pelos modelos. Cada linha representa o parâmetro de nosso interesse $\rho(r h o)$, com exceção da primeira linha de cada tabela, que informa o parâmetro $\delta$ (gamma), que indica a prevalência (tamanho) daquela classe latente na amostra. Os erros padrão foram omitidos porque eles eram inferiores a zero, zero, logo, irrelevantes na avaliação dos coeficientes reportados nas tabelas.

Os resultados da modelagem estão apresentados nas tabelas e os que mais se destacam, apresentados nos gráficos abaixo. De forma geral, podemos destacar que 


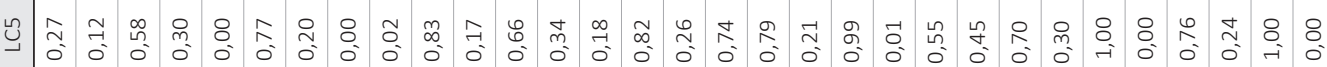

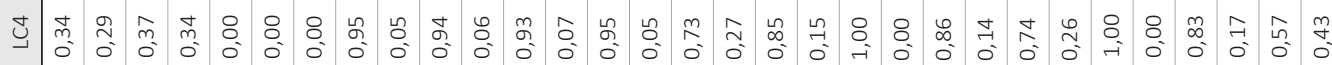
虫

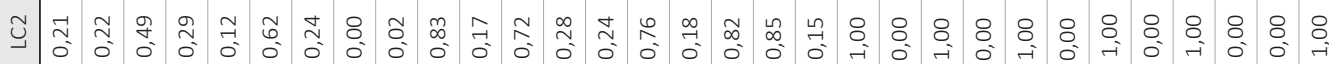

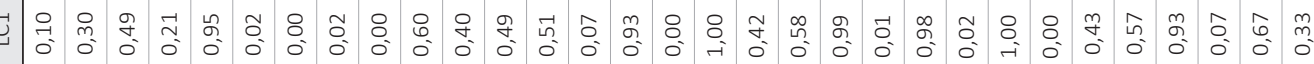

J

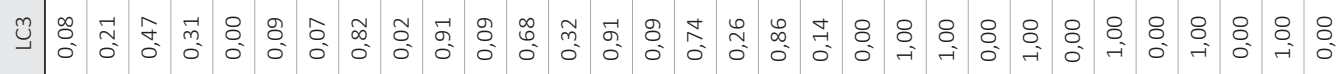
$\tilde{3}$

舀

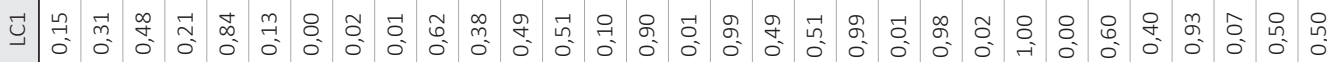

0

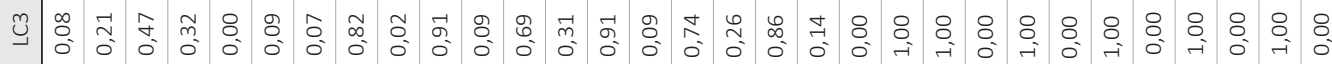
㟧

⿹

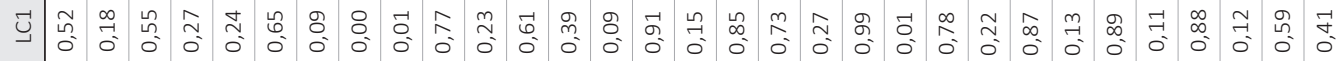
号

บ 气

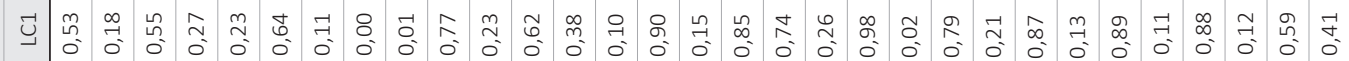

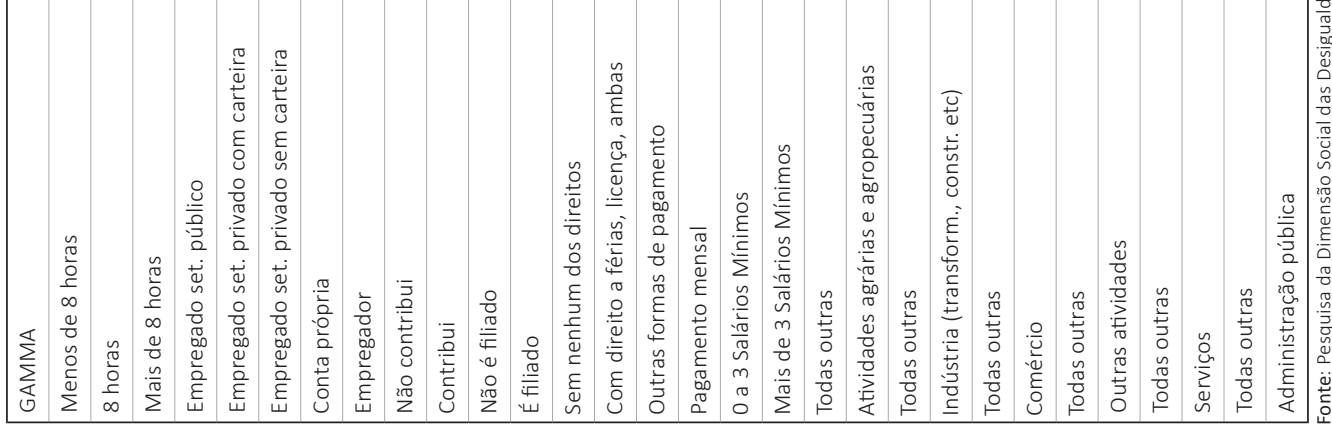


nem todos os indicadores elencados são interessantes para o nosso exercício. Parâmetros $\rho$ (rho) inferiores a 0,5 são considerados relativamente fracos no ajuste dos modelos. Se estivéssemos em um quadro que emulasse a análise fatorial, eliminaríamos esses indicadores da análise. No entanto, nossa opção não é essa, pois a força de associação das variáveis escolhidas com as classes latentes é um dos resultados que desejamos apresentar, dado o ineditismo da disponibilidade de dados com essa qualidade. Sendo assim, mantivemos esses indicadores na apresentação da tabela para que sua relevância para o tipo de caracterização ocupacional que pretendem captar fique explícita. Além disso, como certas variáveis influenciam o "agrupamento" gerado pela análise, mesmo na ausência de um resultado significativo ao final, elas cumprem um papel de ajuste e por isso, são mantidas no modelo. Quais são os principais resultados que surgem a partir do ajuste desses modelos? Iremos analisar os resultados a partir de duas classes latentes até alcançarmos cinco. Ficaremos limitados à variável mais significativa para a discussão, que é a posição na ocupação, no sentido de poupar espaço. Ao nos determos na análise dessa variável, conseguimos destacar o que emerge de mais significativo no padrão de associação das variáveis escolhidas.

\section{GRÁFICO 1}

RESULTADO DA ANÁLISE DE CLASSES LATENTES COM DOIS PARÂMETROS AJUSTADOS. PARÂMETROS rho DA VARIÁVEL POSIÇÃO NA OCUPAÇÃO

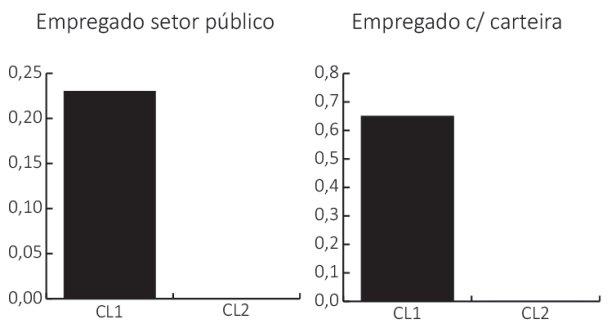

Empregado s/ carteira

Conta própria

Empregador
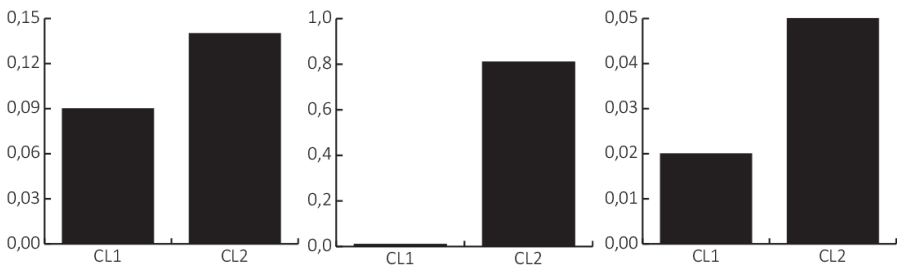

Fonte: Pesquisa da Dimensão Social das Desigualdades, elaboração própria.

No primeiro passo, com duas classes latentes ajustadas, a principal fronteira que emerge é a da formalidade e da informalidade, como aponta o Gráfico 1. As variáveis observadas que se relacionam ao emprego com carteira assinada ou na administração pública se agrupam em uma classe latente, enquanto os sem carteira e os 
conta própria agrupam-se em outra. Ao ajustar o modelo com três classes latentes, o resultado se mantém. O parâmetro adicional incorpora um grupo à análise de perfil praticamente idêntico à classe latente que captava os "conta própria" no passo anterior. Com o auxílio da Tabela 4, podemos perceber que a classe latente adicional ajustada se relaciona ao autoemprego rural, ou seja, estabelece uma fronteira setorial (rural e não rural) junto àqueles que estão envolvidos com o autoemprego. No entanto, a principal fronteira identificada anteriormente mantém-se, a análise continua mostrando uma polarização entre o emprego e o autoemprego.

\section{GRÁFICO 2}

RESULTADO DA ANÁLISE DE CLASSES LATENTES COM TRÊS PARÂMETROS AJUSTADOS.

PARÂMETROS rho DA VARIÁVEL POSIÇÃO NA OCUPAÇÃO

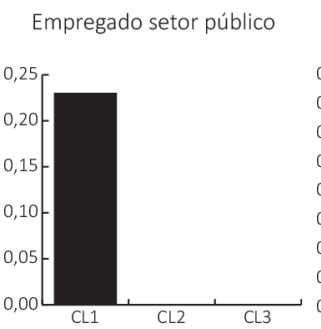

Empregado c/ carteira

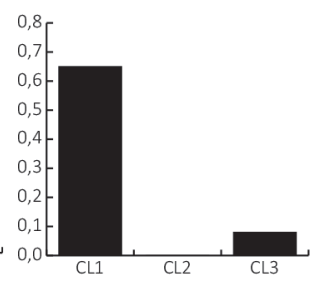

Empregado s/ carteira

Conta própria

Empregador
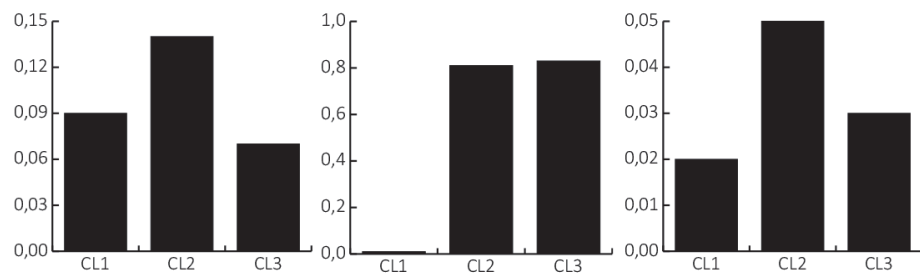

Fonte: Pesquisa da Dimensão Social das Desigualdades, elaboração própria.

A seguir, adicionamos o quarto parâmetro, ajustamos um modelo com quatro classes latentes, representado no Gráfico 3. Surge então uma divisão no grupo relacionado ao emprego, com a emergência de uma divisão setorial importante, que se relaciona ao emprego público. No Gráfico 4 são apresentados os resultados relativos ao ajuste de um modelo com cinco parâmetros. A nova classe latente ajustada não apresenta resultados significativamente distintos dos alcançados previamente, há uma redundância entre as classes latentes dois (CL2) e cinco (CL5), como uma inspeção visual da importância das barras do Gráfico 4 nos mostra, e o recurso à Tabela 4 endossa.

Sendo assim, iremos prosseguir nossa análise com um escrutínio do modelo mais simples, com quatro classes latentes ajustadas. 
GRÁFICO 3

RESULTADO DA ANÁLISE DE CLASSES LATENTES COM QUATRO PARÂMETROS AJUSTADOS. PARÂMETROS $r h O$ DA VARIÁVEL POSIÇÃO NA OCUPAÇÃO

Empregado setor público Empregado c/ carteira
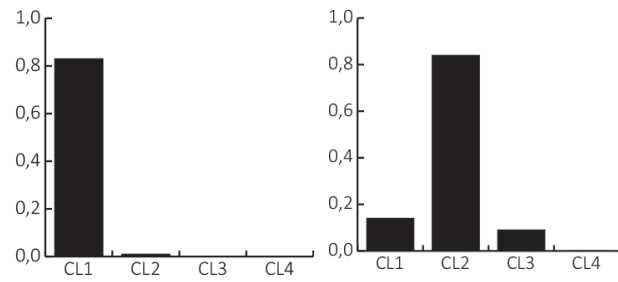

Empregado s/ carteira

Conta própria

Empregador
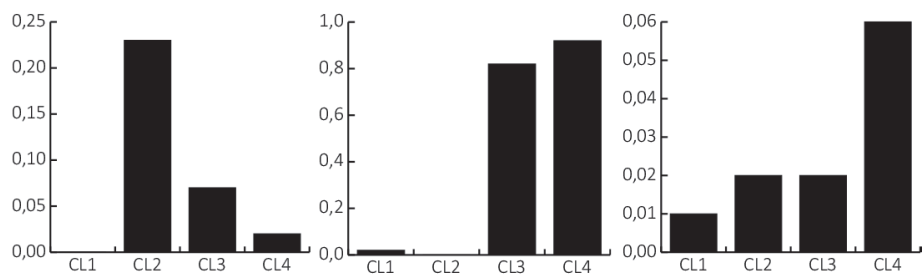

Fonte: Pesquisa da Dimensão Social das Desigualdades, elaboração própria.

GRÁFICO 4

RESULTADO DA ANÁLISE DE CLASSES LATENTES COM CINCO PARÂMETROS AJUSTADOS. PARÂMETROS $r h o$ DA VARIÁVEL POSIÇÃO NA OCUPAÇÃO

Empregado setor público Empregado c/ carteira
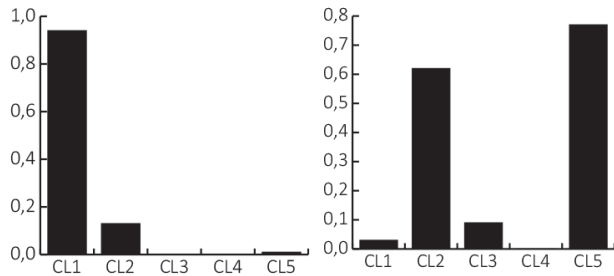

Empregado s/ carteira

Conta própria

Empregador
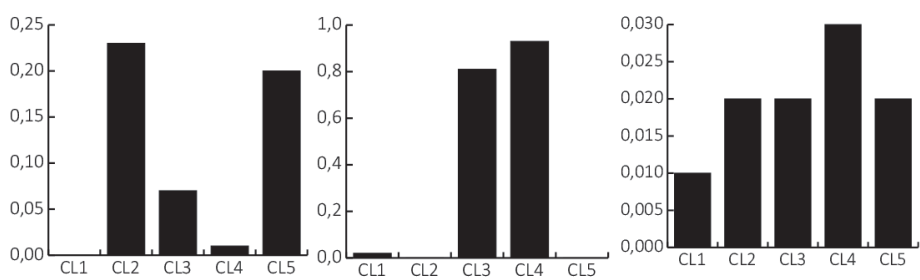

Fonte: Pesquisa da Dimensão Social das Desigualdades, elaboração própria. 
Ao identificar o número de parâmetros que melhor se ajusta aos nossos dados e escolhido um resultado para focar a análise, prosseguimos com uma caracterização dessas classes latentes, através da inspeção de sua associação com os outros indicadores utilizados na análise. Um primeiro resultado significativo que pode ser apontado é que as classes latentes captam clivagens previsíveis do mercado de trabalho brasileiro. A mais geral é a divisão entre emprego e autoemprego, e essa divisão, por sua vez, também pode ser fragmentada, cada uma em dois grupos distintos. Entre os empregados, aparece a divisão entre os empregados com carteira e aqueles do setor público e entre os conta própria; entre aqueles ligados a atividades rurais e urbanas. Essa distinção representa a conhecida dualidade do mercado de trabalho brasileiro, dividido entre a formalidade e informalidade.

Nos Gráficos 5 e 6, a seguir, selecionamos atributos que caracterizam as classes latentes, variáveis que foram utilizadas nas análises para ajuste dos modelos ${ }^{5}$. Sua análise permite-nos qualificar de forma mais profunda as interpretações necessárias para o entendimento do resultado do ajuste do modelo. Os padrões que emergem são claros. À esquerda, temos duas classes latentes, CL1 e CL2, que captam situações relacionadas ao emprego. Ambas agrupam situações nas quais há predominantemente pagamento mensal e direito a férias, licença ou ambas. O que as

\section{GRÁFICO 5}

RESULTADO DA ANÁLISE DE CLASSES LATENTES COM QUATRO PARÂMETROS AJUSTADOS. PARÂMETROS rho DAS VARIÁVEIS DE CONTRIBUIÇÃO PREVIDENCIÁRIA, FILIAÇÃO SINDICAL, DIREITO A FÉRIAS E/OU LICENÇA, TIPO DE PAGAMENTO

Contribui Previdência

Filiado a sindicato
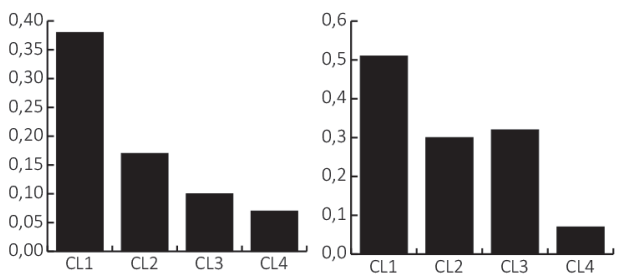

Férias, licença ou ambas

Pagamento mensal

> de 2 salários mínimos
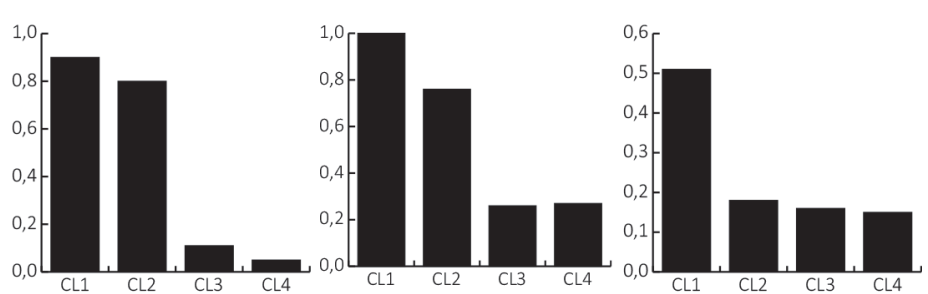

5. Ao contrário dos gráficos anteriores, em que a soma da porcentagem das barras das diferentes classes latentes somava $100 \%$, nos gráficos a seguir as barras podem atingir esse valor sozinhas. Isso se deve ao fato de que as variáveis foram inseridas como dummies no modelo, de forma que $o$ padrão de variação se tornasse mais claro para a análise.

Fonte: Pesquisa da Dimensão Social das Desigualdades, elaboração própria. 
distingue é a contribuição previdenciária, a filiação sindical e o nível salarial. A CL1 é mais protegida em comparação à $C L 2$, o que emerge pelo fato de ela ser composta por empregados do setor público. As CL3 e CL4, por sua vez, são bastante parecidas e se diferenciam, basicamente, pelos diferentes níveis de associação sindical. Ao analisar o Gráfico 6 é possível completar o quadro de entendimento sobre o que cada uma dessas classes latentes representa. Podemos ver que a CL1 é formada predominantemente por atividades classificadas como pertencentes à administração pública ou reunidas no termo "outras". A CL2, por sua vez, é mais heterogênea em sua composição por setor de atividade: todas as opções presentes na amostra, com exceção das atividades rurais e aquelas reunidas no código "outras", estão presentes. Isso se repete na CL4. A CL3, por sua vez, é exclusivamente rural.

\section{GRÁFICO 6}

RESUltAdO DA ANÁLISE DE CLASSES LATENTES COM CINCO PARÂMETROS AJUSTADOS. PARÂMETROS rho DAS VARIÁVEIS DE TIPO DE ATIVIDADE ECONÔMICA

Atividades agropecuárias

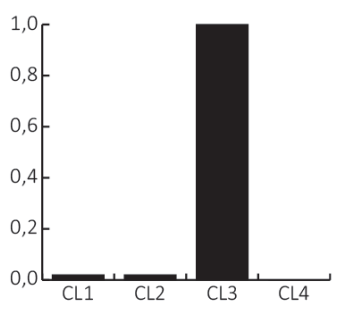

Outras atividades

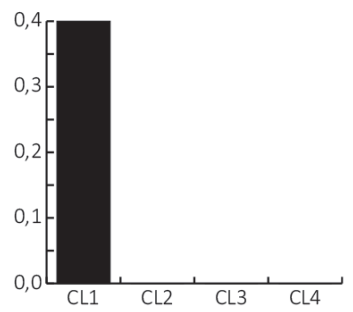

Indústria (trans., construção...)

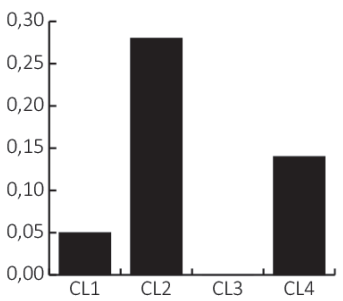

Serviços

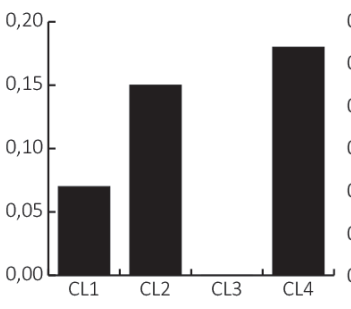

Comércio

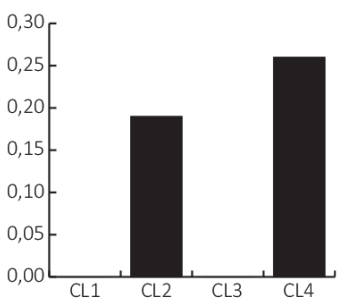

Administração pública

Fonte: Pesquisa da Dimensão Social das Desigualdades, elaboração própria.

Podemos, com os resultados analisados até o momento, fazer um pequeno resumo das principais características que emergem a partir das análises selecionadas. Com efeito, o principal resultado encontrado foi uma clara divisão entre os conta própria e os empregados, independentemente do número de classes latentes ajustadas. Dada essa grande fragmentação, cada grupo ainda é dividido em outros dois, que diferenciam dois mundos: "mundo do emprego" e o "mundo dos conta própria". Ao analisarmos as características de cada uma das quatro classes latentes, podemos 
constatar que a CL1 é a mais formalizada, a partir dos indicadores disponíveis, na análise e é predominantemente formada por empregados com carteira assinada e da administração pública. A CL2 é relativamente parecida, mas apresenta um nível de formalização menor e é dominada por empregados do setor privado com carteira assinada. A CL3 é a classe latente mais homogênea, é predominantemente rural e composta por aqueles envolvidos com o autoemprego, assim como a CL4, que, todavia, tem uma composição heterogênea do ponto de vista das atividades. Em conjunto, podemos afirmar com segurança que esses resultados são consistentes com o quadro de formação do mercado de trabalho brasileiro, oferecendo dele uma boa descrição.

Dada essa coerência, acreditamos que os resultados são confiáveis para empreender a avaliação que desejamos, que é uma tentativa de entender a pertinência da tipologia ocupacional EGP para o contexto brasileiro. Na Tabela 5 e no Gráfico 7, temos os resultados condensados. O primeiro ponto a se destacar é a congruência entre a tipologia ocupacional EGP e a captação dos conta própria e sua divisão setorial. As classes latentes que captam esse tipo de situação associam-se às categorias esperadas na tipologia, principalmente para os conta própria rurais. Com uma precisão relativamente menor, mas satisfatória, o mesmo ocorre para a CL4. No entanto, é de se ressaltar que categorias não esperadas da tipologia também se fazem representar na classe latente, como é possível identificar para as categorias I, II e Illa da tipologia EGP.

TABELA 5.

RESULTADOS DOS MODELOS DE ANÁLISE DE CLASSES

LATENTES COM QUATRO PARÂMETROS AJUSTADOS.

PARÂMETROS rho DA TIPOLOGIA OCUPACIONAL EGP

\begin{tabular}{|c|c|c|c|c|c|}
\hline & & & & \\
\hline & & LC1 & LC2 & LC3 & LC4 \\
\hline I: & Profissionais, alto nível & 0,24 & 0,06 & 0,00 & 0,06 \\
\hline II: & Profissionais, baixo nível & 0,26 & 0,10 & 0,00 & 0,09 \\
\hline IIla: & Não manual de rotina & 0,21 & 0,07 & 0,00 & 0,10 \\
\hline IIIb: & Serviços e vendas & 0,03 & 0,13 & 0,00 & 0,00 \\
\hline IVa: & Conta própria com empregados & 0,00 & 0,00 & 0,01 & 0,23 \\
\hline IVb: & Conta própria sem empregados & 0,00 & 0,00 & 0,01 & 0,47 \\
\hline $\mathrm{V}:$ & Supervisores do trabalho manual & 0,01 & 0,04 & 0,00 & 0,00 \\
\hline VI: & Trabalhador manual qualificado & 0,06 & 0,12 & 0,00 & 0,00 \\
\hline VIlla: & Trabalhador manual não qualificado & 0,19 & 0,48 & 0,01 & 0,03 \\
\hline VIIb: & Trabalhadores agrários & 0,00 & 0,01 & 0,17 & 0,00 \\
\hline IVc: & Conta própria agrário & 0,00 & 0,00 & 0,81 & 0,02 \\
\hline
\end{tabular}


GRÁFICO 7

PARÂMETROS $r$ rho DA VARIÁVEL EGP PARA OS MODELOS COM QUATRO CLASSES LATENTES. ASSOCIAÇÃO DA TIPOLOGIA OCUPACIONAL COM OS PARÂMETROS ESPECIFICADOS

I. Profissionais, nível alto

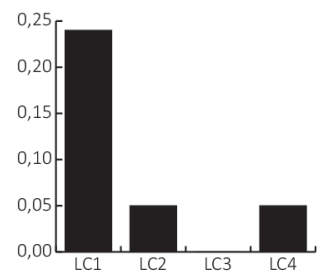

II. Profissionais, nível baixo

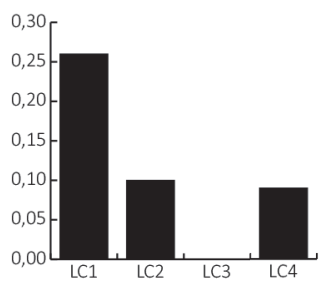

IIla. Não manual de rotina

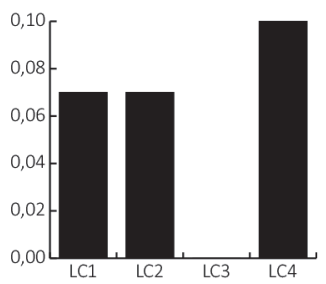

IVb. Conta própria s/ empreg.

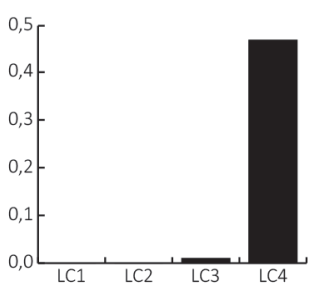

Vlla. Trab. manual não qualif.

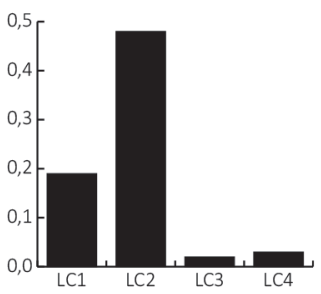

IIIb. Serviços e vendas

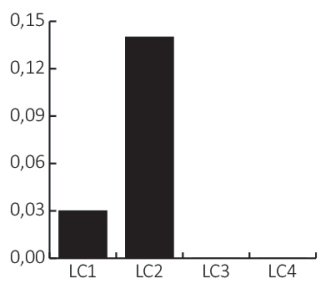

V. Supervisor de trab. manual

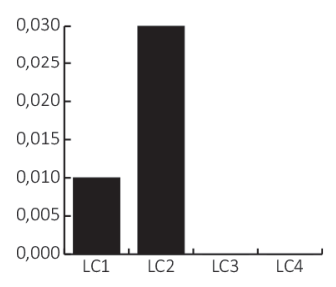

VIIb. Trabalhadores agrários

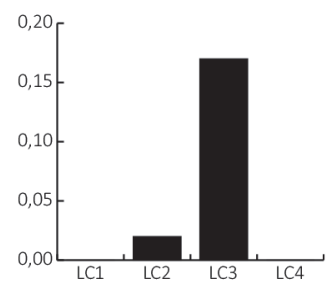

IVa. Conta própria c/ empreg.

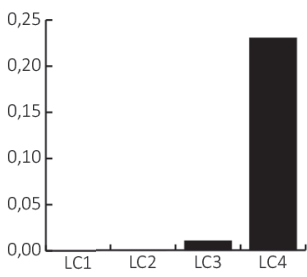

VI. Trab. manual qualificado

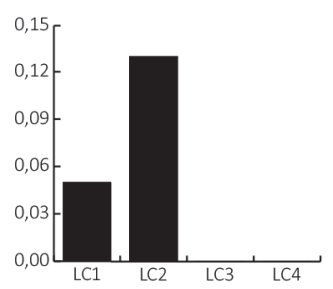

VIlc. Conta própria agrário

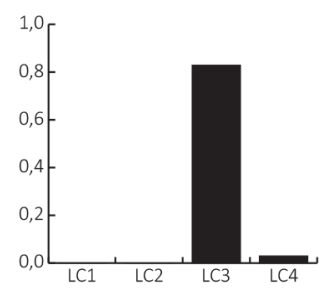

Fonte: Pesquisa da Dimensão Social das Desigualdades, elaboração própria.

A heterogeneidade do mercado de trabalho brasileiro se faz representar nas associações entre a tipologia ocupacional e as classes latentes. Se começamos a análise seguindo crescentemente a organização dos algarismos romanos da categoria, as classes I, II e IIla se agrupam com mais força na CL1, o que é relativamente previsível. No entanto, elas estão igualmente representadas nas CL2 e CL4. Como argumenta- 
mos anteriormente, a CL2 também está vinculada ao emprego, logo, seria natural haver um certo resíduo de associação entre essas categorias e essa classe latente. No entanto, a associação entre essas categorias e a CL4 - que reflete fundamentalmente situações de autoemprego -, não é esperada. Isso se deve, provavelmente, à relativa heterogeneidade das ocupações que compõem essas três categorias e que não necessariamente se vinculam ao mercado de trabalho pelo emprego. Como no Brasil há formas de inserção que tentam flexibilizar os vínculos trabalhistas, mesmo nas ocupações mais prestigiadas elas acabam se associando à classe latente que capta a situação de autoemprego.

Uma situação parecida emerge com a categoria VIla ("trabalhador manual não qualificado"). Ela se associa tanto à CL1 como à CL2. Como essa é uma categoria muito expressiva em termos de sua representatividade no mercado de trabalho brasileiro, ocupando $25 \%$ da amostra, parte dos ocupantes desta posição de classe acaba por se fazer representar na classe latente que expressa uma situação mais formal e estável, como é o caso da CL1. O tamanho dessa categoria mostra como a tipologia agrupa as diferentes inserções ocupacionais do mercado de trabalho brasileiro sob um mesmo rótulo, excessivamente grande. Essa representatividade da categoria acaba mascarando as outras inserções ocupacionais representativas de contratos de trabalho, que granjeiam uma importância residual nas associações com as classes latentes.

Dados esses padrões de associação, é possível afirmar que a tipologia ocupacional funciona apenas parcialmente para os dados brasileiros. Apesar de ser sensível à presença do autoemprego, a tipologia não tem padrões claros de associação para as fronteiras que pretende captar: as divisões presentes no mercado de trabalho, reguladas por diferentes tipos de "contrato" - serviço (service) e trabalho (labour). Essa situação não se reflete nos dados mobilizados no presente artigo, toda heterogeneidade de nosso contexto fica resumida a poucas categorias muito divergentes, principalmente a de "trabalhador manual não qualificado" e "conta própria sem empregados". Apesar de a análise ser sensível aos pontos destacados pela literatura como marcantes do mercado de trabalho brasileiro - principalmente as marcas da informalidade -, essa característica se faz presente na análise sobretudo através dos conta própria. A tipologia é pouco sensível à massa de trabalhadores que recorre a vias mercantis como estratégia de trabalho, a principal contribuição analítica implícita na tipologia, de eixos de serviço e trabalho que representariam a comodificação do trabalho não é a principal saliência empírica que emerge dos dados brasileiros. 


\section{Discussão e conclusão}

Ao longo do trabalho apresentamos os contornos analíticos da estratégia de argumentação sociológica chamada análise de classes. Apresentamos essas abordagens e uma forma particular de operacionalizar os agregados ocupacionais, a tipologia EGP, que é amplamente utilizada na literatura internacional, mas não o é no Brasil. Adotamos um entendimento eclético do que seja a análise de classes e, ao invés de nos determos nos ruídos presentes nas diferentes propostas internacionais e nacionais, procuramos destacar o que há de comum entre elas. Nossa avaliação apresenta ainda uma orientação pragmática, já que tiramos proveito da disponibilidade de dados inéditos para a realização dos modelos apresentados ao longo do artigo.

Perguntamo-nos se essa classificação ocupacional utilizada, realizada a partir de pesquisas internacionais e focada em mercados de trabalho bastante distintos, sustenta-se para o caso brasileiro. Inspirados pela literatura sociológica sobre estratificação social e mercados de trabalho, questionamos se o contexto brasileiro não inviabilizaria a utilização da tipologia. Acreditamos que os resultados apresentados mostram que as ressalvas feitas, inspiradas na literatura mobilizada, tem ressonância empírica. Acreditamos que o principal resultado que encontramos foi a explicitação da marca da informalidade no mercado de trabalho brasileiro e como ela se relaciona com a tipologia ocupacional utilizada. Por um lado, o esquema EGP tem um bom desempenho na captação de situações que se relacionam com o autoemprego, mas, por outro, não consegue captar de forma clara tendências representativas ao emprego, o que, supostamente, a tipologia faria por definição.

Outro resultado que chama a atenção, associado ao que mencionamos no parágrafo anterior, mas relacionado também a outras variáveis, deve-se às variáveis relacionadas à administração pública. Se nos permitirmos uma extrapolação que não atribui esse resultado a erros de mensuração dessas variáveis, podemos apontar que isso se deve a uma heterogeneidade de contração do setor público. De um lado, teríamos o regime de contratação de concursados, com alta estabilidade, salários e direitos; de outro, há os indivíduos que prestam serviços para o setor público, mas não são concursados. As duas situações implicam posições de classe distintas, como acreditamos ter ficado refletido nos resultados de nossa modelagem. O papel dessa dimensão é o resultado não trivial alcançado em nossa análise. Essa não é uma dimensão que foi incorporada sistematicamente na literatura brasileira sobre análise de classes, o que nos parece grave, tanto pelas consequências empíricas, mas também por considerações sociológicas mais gerais. Esse tipo de evidência aponta para o papel direto do Estado na estruturação de posições no mercado de trabalho e na geração da desigualdade. Certamente, essa é uma via 
de reflexão interessante e promissora, que toca em outros temas mais gerais que, infelizmente, não são o foco de nosso argumento presente.

Tendo em vista os resultados alcançados e a literatura com a qual dialogamos, um resultado substantivo que surge a partir do presente trabalho é endossar as precauções feitas por outros pesquisadores na operacionalização de tipologias ocupacionais para o mercado de trabalho brasileiro. Os desafios que marcam a formação de nossa estrutura ocupacional devem ser diretamente incorporados na operacionalização da tipologia, e propostas mais genéricas e menos específicas, como é o caso do EGP, têm limites claros para a análise de um contexto como o nosso. De todo modo, acreditamos ter demonstrado a necessidade de avaliar essa dimensão. Igualmente, pesquisadores de outras áreas interessados em incorporar tipologias ocupacionais em seus trabalhos empíricos encontram no presente trabalho ressalvas que podem lhes ser úteis ao lidar com este tema, sociológico por excelência. Como sugestão, ao final de nossa reflexão, sugerimos que colegas da mesma forma empiricamente orientados apresentem de forma mais clara seus critérios de operacionalização e se preocupem, como tentamos fazer no presente trabalho, com critérios de validade interna dos conceitos que trabalham.

Abstract: The concept of social class is one of the pillars of sociological arguments of many flavors. In this article, we focus on this classical heuristical tool and implement an empirical oriented analysis to test its validity. Our effort is focused on an empirical assessment of the class typology known as EGP (Erikson-Goldthorpe-Portocarero). Through the use of methodological tools coherent with the pattern of avaiable data, we provide results about the association of the typology with relevant aspects of the Brazilian labor market. The main result of this analysis is that there are serious limitations to the use of the evaluated typology in the Brazilian context. We argue that researchers interested in making use of this concept should be very careful and think thoroughly about how the Brazilian context imposes serious limits to the concept of social class operationalized via the EGP scheme.

Keywords: labor market, class analysis, occupational typologies, social class, EGP.

\section{Referências}

BIRKELUND, Gunn Elisabeth; GOODMAN, Leo A.; ROSE, David. The latent structure of job characteristics of men and women. American Journal of Sociology, v. 102, n. 1, p. 80-113, 1996.

BREEN, Richard. Foundations of a neo-weberian class analysis. In: WRIGHT, E. O. (Ed.). Approaches to class analysis. Cambridge: Cambridge University Press, 2005.

BREEN, Richard; HALPIN, Brendan; ECONOMIC AND SOCIAL RESEARCH INSTITUTE. Subsidising jobs: an evaluation of the employment incentive scheme. Dublin: Esri, 1989. 
BREEN, Richard; ROTTMAN, David. Class stratification: a comparative perspective. New York: Harvester Wheatsheaf, 1995.

CARDOSO, Adalberto Moreira. Transições da escola para o trabalho no Brasil: persistência da desigualdade e frustração de expectativas. Dados, v. 51, n. 3, p. 569-616, 2008.

CARVALHAES, Flavio; SOUZA, Pedro. Análise de classe e a queda da desigualdade de renda do trabalho no Brasil. Revista Plural (USP), v. 21, n. 2, 2014.

CHAN, Tak Wing; BIRKELUND, Gunn Elisabeth; KRISTIAN, Arne Aas; WIBORG, Oyvind. Social status in Norway. European Sociological Review, v. 27, n. 4, p. 451-468, 2011.

CHAN, Tak Wing; GOLDTHORPE, John H. Class and status: the conceptual distinction and its empirical relevance. American Sociological Review, v. 72, p. 512-532, 2007.

COLLINS, Linda M.; LANZA, Stephanie T. Latent class and latent transition analysis with applications in the social, behavioral and health sciences. Hoboken (NJ): Wiley, 2010.

ERIKSON, Robert; GOLDTHORPE, John H. The constant flux: a study of class mobility in industrial societies. Oxford; New York: Oxford University Press; Clarendon Press 1992.

ERIKSON, Robert; GOLDTHORPE, John; PORTOCARERO, Lucienne. Intergenerational class mobility in three Western European societies. British Journal of Sociology, v. 30, n. 4, p. 415-439, 1979.

EVANS, Geoffrey; MILLS, Colin. Identifying class structure. A latent class analysis of the criterion-related and construct validity of the goldthorpe class scheme. European Sociological Review, v. 14, n. 1, p. 87-106, 1998.

- Are there classes in post-communist societies? A new approach to identifying class structure. Sociology, v. 33, n. 1, p. 23-46, 1999.

- In search of the wage-labour/service contract: new evidence on the validity of the Goldthorpe class schema. British Journal of Sociology, v. 5, n. 4, p. 641-661, 2000.

GANZEBOOM, Harry B. G.; TREIMAN, Donald J. Internationally comparable measures of occupational status for the 1988 International Standard Classification of Occupations. Social Science Research, v. 25, p. 201-239, 1996.

GOLDTHORPE, John. On sociology - Illustration and Retrospect. 2. ed. Stanford (CA): Stanford University Press, 2007a.

Social class and the differentiation of employment contracts. In: GOLDTHORPE, J. H. (Ed.). On sociology. 2. ed. V. II, "Illustration and retrospect". Stanford (CA): Stanford University Press, 2007b. 
- Occupational sociology, yes: class analysis, no: comment on Grusky and Weeden's Research Agenda. Acta Sociologica, v. 45, p. 211-217, 2002.

GOLDTHORPE, John H. On sociology: numbers, narratives, and the integration of research and theory. Oxford (UK); New York: Oxford University Press, 2000.

GOLDTHORPE, John H.; MARSHALL, Gordon. The promising future of class analysis: a response to recent critiques. In: MARSHALL, G. O. (Ed.). Social inequality in industrial societies. London: Sage Publications, 1997.

GOLDTHORPE, John H.; MCKNIGHT, Abigail. The economic basis of social class. In: MORGAN, S.;GRUSKY, D. et alii (Eds.). Mobility and inequality - frontiers of research in sociology and economics. Stanford (CA): Stanford University Press, 2006.

GRUSKY, David B.; GALESCU, Gabriela. Foundations of a neo-durkheimmian class analysis. In: WRIGHT, E. O. (Ed.). Approaches to class analysis. Cambridge: Cambridge University Press, 2005.

GRUSKY, David B.; SORENSEN, Jesper. Can class analysis be salvaged? The American Journal of Sociology, v. 103, n. 5, p. 47, 1998.

GRUSKY, David B.; WEEDEN, Kim. Are there social classes? A framework for testing sociology's favorite concept. In: LAREAU, A. e CONLEY, D. (EdS.). Social class. How Does It Work?, 2008.

- Does the sociological approach to studying social mobility have a future? In: MORGAN, S. L.;GRUSKY, D. B., et alii (Eds.). Mobility and inequality - frontiers of research in sociology and economics. Stanford (CA): Stanford University Press, 2006.

GUIMARÃES, Nadya Araújo. Empresariando o trabalho: os agentes econômicos da intermediação de empregos, esses ilustres desconhecidos. Dados, v. 51, n. 2, p. 275311, 2008.

. Por uma sociologia do desemprego. Revista Brasileira de Ciências Sociais, v. 17, n. 50, p. 103-121, 2002.

HAGENAARS, Jacques A.; MCCUTCHEON, Allan L. Applied latent class analysis. Cambridge ; New York: Cambridge University Press, 2002.

LANZA, Stephanie T.; DZIAK, J. J.; HUANG, L; XU, S.; COLLINS, L. M. PROC LCA \& PROC Lta user's guide (Version 1.2.7). University Park: The Methodology Center, Penn State, 2011. Disponível em: <http://methodology.psu.edu>.

MANZA, Jeff; BROOKS, Clem. Does class analysis have anything to contribute to the study of politics. Theory and Society, v. 25, p. 717-724, 1996. 
MCCUTCHEON, Allan L. Latent class analysis. Newbury Park: Sage Publications, 1987.

PAKULSKI, Jan; WATERS, Malcom. The death of class. Theory and Society, v. 25, n. 667-691, 1996.

PORTES, Alejandro. Economic sociology: a systematic inquiry. Princeton (NJ): Princeton University Press, 2010.

PORTES, Alejandro; HALLER, William. The informal economy. In: SMELSER, N. J.; SWEDBERG, R. (Eds.). The handbook of economic sociology. 2, ed. Princeton (NJ); New York: Princeton University Press; Russel Sage Foundation, 2005.

PORTES, Alejandro; HOFFMAN, Kelly. Latin American class structures: their composition and change during the Neoliberal Era. Latin American Research Review, v. 38, n. 1, p. 41-82, 2003.

PROC LCA \& PROC LTA (Version 1.2.7) [Software]. University Park: The Methodology Center, Penn State, 2011. Disponível em: <http://methodology.psu.edu>.

RIBEIRO, Carlos Antônio Costa. Estrutura de classe e mobilidade social no Brasil. Bauru: EdUSC, 2007.

SANTOS, José Alcides Figueiredo. Uma classificação socioeconômica para o Brasil. Revista Brasileira de Ciências Sociais, v. 20, n. 8, p. 27-45, 2005.

SANTOS, José Alcides Figueiredo. Estrutura de posições de classe no Brasil: mapeamento, mudanças e efeitos na renda. Belo Horizonte: Editora UFMG, 2002.

SCALON, Maria Celo Ramos da Cruz. Mobilidade social no Brasil: padrões e tendências. (Tese de Doutorado em Sociologia), Centro de Pesquisas e Ensino de Pós-Graduação em Ciências Sociais (luperj), Rio de Janeiro, 1997.

SILVA, Nelson do Valle. O esquema analítico e a classificação ocupacional. In: HASENBALG, C. e SILVA, N. D. V. (Eds.). Origens e destinos: desigualdades sociais ao longo da vida. Rio de Janeiro: Topbooks, 2003a.

Os rendimentos pessoais. In: HASENBALG, C. e SILVA, N. D. V. (Eds.). Origens e destinos: desigualdades sociais ao longo da vida. Rio de Janeiro: Topbooks, 2003b. SORENSEN, Aage. The structural basis of social inequality. The American Journal of Sociology, v. 101, n. 5, p. 1333-1365, 1996.

TORCHE, Florencia. Una clasificación de clases para la sociedad chilena. Revista de Sociología, v. 20, 2006. 
WEEDEN, Kim; GRUSKY, David. The three worlds of inequality. American Journal of Sociology, v. 117, n. 6, p. 1723-1785, 2012.

WRIGHT, Erik Olin. Approaches to class analysis. Cambridge (UK); New York: Cambridge University Press, 2005a.

- Foundations of a neo-Marxist class analysis. In: WRIGHT, E. O. (Ed.). Approaches to class analysis. Cambridge (UK); New York: Cambridge University Press, $2005 b$.

. Class counts: comparative studies in class analysis. Cambridge, Cambridge University Press, 1997. 
